\title{
Comparative Study of Modified Conical Cavity Receiver With Other Receivers for Solar Paraboloidal Dish Collector System
}

\section{Arjun Singh K}

NIT Puducherry: National Institute of Technology Puducherry

SENDHIL KUMAR NATARAJAN ( $\square$ drsendhil1980iitmuk@gmail.com )

National Institute of Technology Puducherry https://orcid.org/0000-0003-3257-4570

\section{Research Article}

Keywords: cavity receiver, SPDC, modified conical cavity receiver, comparison of receivers, Dish concentrator, Paraboloidal dish

Posted Date: March 2nd, 2021

DOl: https://doi.org/10.21203/rs.3.rs-237950/v1

License: (c) (i) This work is licensed under a Creative Commons Attribution 4.0 International License.

Read Full License 


\section{Collector System}

\section{Arjun Singh K, Sendhil Kumar Natarajan*}

4 Solar Energy Laboratory, Department of Mechanical Engineering,

5 National Institute of Technology Puducherry, Karaikal - 609609, INDIA

6

*Corresponding Author

Email ID: sendhil80@nitpy.ac.in 


\section{Abstract}

10 Solar Parabolic Dish Concentrators are one of the most efficient solar power conversion technologies. The cavity

11 receivers are most common type, used for reducing the heat losses from the receiver. In this paper a novel cavity receiver is proposed and the objective is to compare the novel modified conical cavity receiver with the existing cavity receivers such as cylindrical, conical and modified cavity receivers. The cavity receivers are designed for the parabolic dish of $4 \mathrm{~m}$ diameter which is installed at National Institute of Technology Puducherry, India. Ray tracing analysis is carried out to determine the size of the receiver. The analysis was carried out for various orientations of the receivers from $0^{\circ}$ to $90^{\circ}$ with a step size of $15^{\circ}$ and also for the cavity temperatures: $300^{\circ} \mathrm{C}$, $400^{\circ} \mathrm{C}, 500^{\circ} \mathrm{C}, 600^{\circ} \mathrm{C}$ and $700^{\circ} \mathrm{C}$. Based on the results obtained the modified conical cavity receiver is found to be the best design in terms of minimum heat losses compared to other receivers. The next best choices are found to be modified cavity, conical cavity and cylindrical cavity receiver. The whole analysis is conducted with a developed model in COMSOL Multiphysics.

Keywords: cavity receiver; SPDC; modified conical cavity receiver; comparison of receivers; Dish concentrator; Paraboloidal dish

\section{Introduction}

Solar energy would be an eco-friendly approach to meet the future energy needs of the earth in a sustainable manner. Solar thermal energy collectors are used for productive use of solar thermal energy. Concentrating Solar Power (CSP) is the most viable technology for solar energy usage as it can produce heat at low, medium and high temperatures. Among the CSP technologies, solar parabolic dish collector (SPDC) system attracts many researchers because of its higher solar-thermal conversion efficiency and its modular design capability. Solar parabolic dish is having a wide range of applications such as steam production, electricity production, solar cooling, process heating, desalination (Kaushika and Reddy 2000; Lovegrove et al. 2003; Mancini et al. 2003; John and J. 2015; Reddy et al. 2015c; Srithar et al. 2016) etc. Parabolic dish concentrator, receiver or absorber and dual axis solar tracker are the three main components of SPDC system (Reddy et al. 2015a; Sahu et al. 2020). The losses and inaccuracies in each component significantly affect the overall efficiency of the collector system. However, a lot of research works are going on to reduce the losses and to improve the accuracies of components. Chong and Wong presented a generalized mathematical method for sun tracking which also improves the accuracy of the tracking system (Chong and Wong 2009). Bakos, performed an experimental study on the electromechanical based dual axis tracking system for parabolic trough collector. The author claimed that it was economical, require low maintenance and simple installation (Bakos 2006). Barker et al., proposed a dual axis 
sun tracker with linear actuation profile which uses four linear actuators with linkages (Barker et al. 2013). Walter et al., reviewed the challenges faced in solar tracking and discussed the advancements (Nsengiyumva et al. 2018). Likewise, a lot of research works on parabolic dish was being carried out based on the improvement of reflectivity, reducing the surface slope error, uniformity in flux distribution, ease of fabrication and installation, economic viability and so on (Sup et al. 2015; Coventry and Andraka 2017; Hafez et al. 2017). Yan et al. proposed an optimization method for the novel discrete solar parabolic dish concentrator intended to improve the flux distribution on the cylindrical cavity receiver and observed an significant reduction in the non-uniformity to 0.10 $\sim 0.22$ (Yan et al. 2018). Hamza et al. developed SPDC system in low cost by optimizing the size of the supports and reflectors to reduce the total weight of the system and concluded that the design was robust and can be implemented for bigger size dishes also (Hijazi et al. 2016). Lifang and Steven presented a new design approach for the parabolic dish concentrator with flexible petals in order to increase the accuracy of the profile and to reduce the fabrication and transportation expenses. Also, claiming that the concept provides a solution to improve the precision of the dish at low cost (Li and Dubowsky 2011). In a technical note presented by Kaushika, the basic geometrical optic relations for parabolic dish concentration with multi-facets (Kaushika 1993). Wang et al. proposed a 2-stage parabolic dish concentrator based on overlap method in order to reduce the receiver size and for improving the flux concentration and distribution (Wang et al. 2017).

The losses from the receiver or absorber is one of the significant factors which affect the overall efficiency of the SPDC system. The dominant heat loss from the receiver is radiant heat loss, followed by convective heat loss and conductive loss respectively. Cavity receivers are most commonly used receivers in dish collector systems. These receivers capture the reflected rays from the concentrator more effectively by multiple internal reflections. Cylindrical (Wang et al. 2013; Azzouzi et al. 2017; Karimi et al. 2018; Loni et al. 2018b, a; Soltani et al. 2019), conical (Li et al. 2015a; Pavlovic et al. 2018; Awasthi and Khan 2019), spherical (Si-Quan et al. 2018), modified cavity receivers (Sendhil Kumar and Reddy 2007a; Reddy and Sendhil Kumar 2008, 2009; Vikram and Reddy 2014, 2015; Reddy et al. 2015c, b, 2016) are some of the frequently used receiver types.

Sendhil Kumar et al. numerically investigated the convective heat losses in a hemispherical cavity receiver for different inclinations $\left(0-90^{\circ}\right)$ for both configuration of with insulations and without insulations. It was then observed that the inclinations of the receiver at $0^{\circ}$ had higher convective losses and gradually decreased eventually moving the angle to $90^{\circ}$ in terms of Nusselt's number correlation (Sendhil Kumar and Reddy 2007b). Melchior et al. investigate about thermochemical reactions using a cylindrical cavity receiver. Results from both experimental and numerical simulations hold the good argument that the major losses were radiative through the 
aperture and conduction through the cavity walls. The set attained a solar to chemical energy conversion of $28.5 \%$ for the temperature of the reactor at $2300 \mathrm{~K}$ and input solar power of $40 \mathrm{~kW} / \mathrm{m}$ (Melchior et al. 2008). Prakash et.al proved that the convective loss increases with increase in mean receiver temperature and decreases with the increase in receiver inclination. The wind-induced convective losses are generally higher than the no-wind convective loss at all receiver inclination angles, except for $0^{\circ}$ inclination angle (Prakash et al. 2009). Prakash et al proposes an estimate for identifying the zone boundary and a variable called "critical air temperature gradient" $(\psi)$ is defined for the same purpose. A value of about 0.3 critical air temperature gradient is observed after the tests. The stagnation zone is observed at regions having $\psi>=0.3$ and convective zone having $\psi>0.3$ (Prakash et al. 2010). Thirugnanasambandam et al. reviews about the present day solar technologies (Thirugnanasambandam et al. 2010). Also, many researchers have discussed the performance analysis of existing geometries, simulations and suggested improvements. The convection heat loss significantly reduces the thermal efficiency and it is important to assess the same and progress in this area (Wu et al. 2010).

Convective heat losses in various shapes (conical, cylindrical, cone-cylindrical and hetero-cylindrical) are compared under various temperatures $(523 \mathrm{~K}, 723 \mathrm{~K}$, and $923 \mathrm{~K})$ at different angles $\left(30^{\circ}, 45^{\circ}, 60^{\circ}\right.$, and $\left.90^{\circ}\right)$. The wind direction speeds in the range of 1 to $5 \mathrm{~m} / \mathrm{s}$. Among all the variants, conical seems to have the lowest convective heat loss coefficient (Jilte et al. 2014). Li et al state that the buoyancy force of air plays a major role in the convective heat losses in a solar parabolic dish operating under $900 \mathrm{~K}$ to $1200 \mathrm{~K}$. 3D numerical simulations were done in the viewpoint if Field Synergy Principle (FSP) to study the heat transfer and heat loss in a cavity receiver. It was also concluded that smaller production of velocity vector and temperature gradient will lead to lower Nusselt number. Local heat transfer performance was done using fluid motion (Li et al. 2015b). Ngo et al observed that heat loss is greatly influenced by the inclination of the receiver and radiative loss is influenced the most by cavity receiver properties. Also, radiative heat loss is found to be constant for all angles. So, optimization of the receiver was done by placing fins in places to reduce radiative loss (Ngo et al. 2015a). Ngo et al. continued work further by a numerical model where a 3D model is made to capture heat transfer and the flow process is analysed. The analysis is further used to optimize the receiver. This paper concludes that heat loss can be reduced by using plate fins (Ngo et al. 2015b). Reddy et al. creates a 3-D numerical model to study combined heat losses in a modified cavity receiver that is to be used for steam generation conditions. The convective heat loss is determined by the estimated Nusselt number correlation developed for the model. The effect of the receiver by receiver inclination, operating temperature, cavity cover emissivity, receiver thickness of insulation was investigated to analyse the combined heat losses. Reddy et al. concludes his paper by determining the natural 
99

100

101

102

103

104

105

106

107

108

109

110

111

112

113

114

115

116

117

118

119

120

121

122

123

124

125

126

127

convection, forced convection and surface radiation heat loss in the modified cavity receiver under various conditions (Reddy et al. 2015d).

Daabo et al. establishes a new relationship between the heat flux distribution on the internal surface and the optical efficiency. The conical shape again proved to exhibit high efficiency $(75.35 \%)$ followed by cylindrical $(71.5 \%)$ and spherical (70.1\%) shapes. The theory concluded that the focal point location depends on the shape of the cavity receiver and the absorptivity in (Daabo et al. 2016). Reddy et al. performed an investigation on convective heat losses in a modified cavity receiver for the effect of wind speed and direction with varying receiver directions $\left(-90^{\circ}\right.$ to $\left.90 \mathrm{deg}\right)$, wind speed $(\mathrm{V}=0-10 \mathrm{~m} / \mathrm{s})$, receiver inclinations (0-90deg) and surface temperatures. A critical wind speed $(5 \mathrm{~m} / \mathrm{s})$ was achieved below which there is no forced convective heat loss. The investigations came up with a variety of conclusions that stated that the heat loss from the receiver is maximum for the side on wind conditions compared to the head-on and back on conditions also the forced convection heat loss was maximum at $60^{\circ}$ inclination irrespective of the wind direction. All these conclusions were made possible with the help of Nusselt number correlations in (Reddy et al. 2016). Arrif et al. investigated numerically the convective heat losses in a cylindrical solar cavity receiver using three helical tube diameters $(12 \mathrm{~mm}, 16 \mathrm{~mm}, 25 \mathrm{~mm})$ and three aperture ratios $(1,0.75$ and 0.5$)$. The effect of certain parameters such as receiver inclination, inlet temperature, and receiver size and tube diameter on the convective heat loss and outlet temperature were analysed. The observations showed a similar conclusion that the convective heat losses increased independently with the increase in diameter, opening ratio and fluid temperature (Arrif et al. 2018). Song yang et al. compares two-cavity heat-pipe receivers, one a conventional type and another a modified novel type. The latter model was subjected to both optical and thermal efficiency simulations to analyse the design and performance of the same. The results proved that the novel model had a better conversion efficiency (68.6\%) than the conventional counterpart. Also, the novel 2 stage dish concentrator improved the uniform incident irradiation distribution on the absorbing surface by the overlapping effect. The optical and thermal performance of the novel design improved as the losses decreased by 18.8\% than the conventional design (Yang et al. 2018a). S. Yang et al. extend his work on reducing the convective heat losses from the cavity receiver for forced convection. A modified cylindrical cavity receiver approved by Australian national university (ANU) was selected for the experiment and the CFD tool was used. A 3-D CFD simulation in Fluent 17.0 for calculating the convective heat loss was preferred to get more accurate results. Different inclination angles and the temperature was given input to run simulations. The forced air circulation system showed 58\% less convective heat loss than the natural air circulation conditions (Yang et al. 2018b). 
128 A lot of research has been conducted on the Solar parabolic dish collector system to improve performance and

129 reduce development costs. A number of researches is being conducted on the receiver part, the parabolic

130 concentrator part and the tracking system. Heat losses from the receiver have been described as the main factor

131 influencing the efficiency of the system. Cavity receivers are found to be the most common configuration for

132 minimising heat losses in the parabolic dish concentrator system. Cylindrical, conical, hemispheric, cubic,

133 modified cavity, etc. are some of the cavity receptors used by many researchers. From the literature review, it has

134 been shown that there is a great deal of scope in the design of different cavity receivers for the solar parabolic dish

135 collection system in order to develop highly efficient designs, especially at different working temperatures. In this

136 paper a new receiver named modified conical cavity receiver is proposed. The novel cavity receiver is then

137 numerically compared with other three known cavity receivers such as cylindrical, conical and modified cavity

138 receiver. The following sections of this paper describes the methodology of simulation work carried out followed

139 by result and discussion and conclusion.

140 2. Methodology

$141 \quad$ 2.1. Ray Tracing

142 In this work, ray tracing of the solar parabolic dish concentrator is carried out initially for the existing $4 \mathrm{~m}$ diameter 143 dish in National Institute of Technology Puducherry, Karaikal $\left(10.92^{\circ} \mathrm{N}, 79.84^{\circ} \mathrm{E}\right)$. From ray tracing analysis the

144 flux distribution of the concentrated fringe over the focal plane is studied with the COMSOL and the concentration ratio is plotted against the $\mathrm{x}$-coordinate. For the analysis, a standard solar direct beam irradiance of $1000 \mathrm{~W} / \mathrm{m}^{2}$ is considered and also solar conical angle, surface slope error due to the placement of square mirror facets are taken into account for the study. The specifications for that dish concentrator and the simulation parameters are given in table 1.

Table 1: Geometrical and simulation parameters considered for the study

\begin{tabular}{llll}
\hline S. No. & Parameters & Symbol & Value \\
\hline 01 & Aperture area of dish & $\mathrm{A}_{\mathrm{p}}$ & $12.535 \mathrm{~m}^{2}$ \\
02 & Diameter of dish aperture & $\mathrm{d}$ & $4.00 \mathrm{~m}$ \\
03 & Focal length & $\mathrm{f}$ & $2.413 \mathrm{~m}$ \\
04 & Rim angle & $\psi$ & $45^{\circ}$ \\
05 & Depth of dish & $\mathrm{h}$ & $0.414 \mathrm{~m}$ \\
06 & Arc length & $\mathrm{s}$ & $6.5719 \mathrm{~m}$ \\
07 & Half conical angle & - & $0.266^{\circ}$
\end{tabular}




$\begin{array}{llll}08 & \text { Reflector } & - & \text { Back silvered mirror } \\ 09 & \text { Reflectivity } & \rho & 0.95 \\ 10 & \text { Thickness of glass } & \mathrm{t} & 0.001 \mathrm{~m} \\ 11 & \text { Facet size } & \mathrm{L} & 0.075 \mathrm{~m} \times 0.075 \mathrm{~m} \\ 12 & \text { Surface slope error } & \sigma & 6.2832 \mathrm{mrad} . \\ 13 & \text { Atmospheric Temperature } & \mathrm{T}_{\infty} & 30{ }^{\circ} \mathrm{C} \\ 14 & \text { Direct beam solar radiation } & \mathrm{I}_{\mathrm{r}} & 1000 \mathrm{~W} / \mathrm{m}^{2} \\ 15 & \text { Conical angle } & \omega_{0} & 0.00465 \mathrm{rad}\end{array}$

\section{2.2. Studied Cavity Receivers}

151 Cavity receivers such as cylindrical, conical, modified cavity receiver, and the novel modified conical cavity 152 receivers have been used for comparative study. Figure 1 shows various cavity receivers used in the current study. 153 A 2D heat transfer laminar flow simulation is conducted using COMSOL Multiphysics for the analysis of the 154 receiver performance. The performance of a receiver is inversely proportional to the losses from the receiver, as the heat loss increases the performance declines.

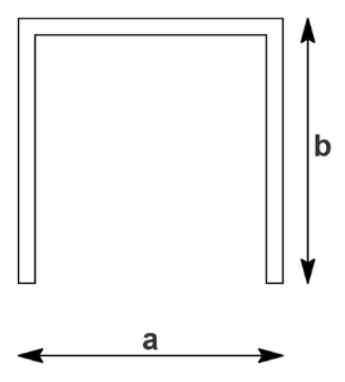

(A)

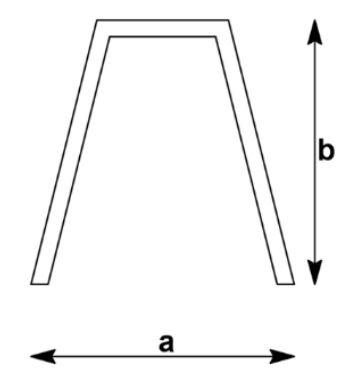

(B)

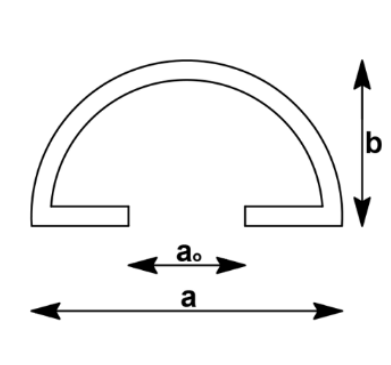

(C)

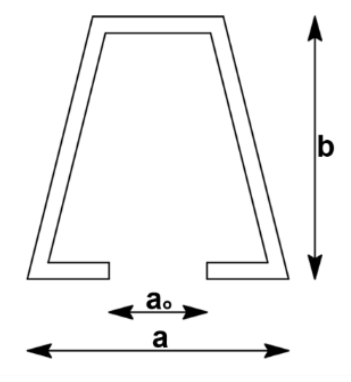

(D)
156

157

Figure 1 Cavity receivers used for the study (A) Cylindrical (B) Conical (C) Modified (D) Modified Conical

$$
\text { Cavity Receivers }
$$

The dimensions for the receiver are chosen based on the radial distribution of the concentration ratio at the focal plane which is explained in detail at section 3.1. The aperture area of all the cavity receivers are kept the same. The height (b) of the receivers are kept same as the aperture diameter (a) except the modified cavity receiver for which the height will be the radius. The aperture opening diameter $\left(a_{0}\right)$ for modified cavity and modified conical cavity receivers were kept same and is also chosen from the distribution of concentration ratio at the focal plane.

\subsection{Mathematical formulations}

The basic equations used for the evaluation of solar parabolic dish collector system can be given as follows: 
166 Available solar radiation on the concentrator can be defined as the product of the projected area of the dish $\left(\mathrm{A}_{\mathrm{p}}\right)$

167 and the direct beam irradiance $\left(\mathrm{I}_{\mathrm{r}}\right)$

$168 Q_{s}=A_{p} \cdot I_{r}$

169 Efficiency of the concentrator can be defined as the ratio of the amount of heat energy concentrator over the focal plane $\left(\mathrm{Q}_{\mathrm{f}}\right)$ to the solar radiation available over the concentrator $\left(\mathrm{Q}_{\mathrm{s}}\right)$

$171 \quad \eta_{\text {con }}=\frac{Q_{f}}{Q_{s}}$

172

Efficiency of the receiver can be defined as the ratio of the amount of energy absorbed by the receiver $\left(\mathrm{Q}_{\mathrm{a}}\right)$ to the energy available over the focal plane $\left(\mathrm{Q}_{\mathrm{f}}\right)$

174

$\eta_{\text {rec }}=\frac{Q_{a}}{Q_{f}}$

175

The optical efficiency of the receiver can be stated as the product of the concentrator efficiency and the receiver efficiency

177

$\eta_{\text {opt }}=\eta_{\text {con }} \cdot \eta_{\text {rec }}$

178 Which can also be given as

$\eta_{o p t}=\frac{Q_{a}}{Q_{s}}$

180 The overall heat loss from the receiver can be given as

$181 Q_{L}=Q_{\text {Conduction }}+Q_{\text {Convection }}+Q_{\text {radiation }}$

182 The overall heat loss coefficient can be calculated based on the following formula

$183 \quad U_{L}=\frac{Q_{L}}{A_{r}\left(T_{r e c}-T_{\infty}\right)}$

The performance of a cavity receiver mainly depends on the losses from the receivers. Hence, overall heat loss coefficient is an ideal index for the evaluation of the cavity receiver.

\subsection{Simulation Model Developed}

187

In the current study the analysis is carried out using COMSOL Multiphysics. In which, the heat transfer and CFD modules are used. The laminar flow and heat transfer in fluids are coupled together to simulate each case under natural convection. No velocity for air domain is given, only flow due to density difference is considered. The Navier-Stokes equation for the conservation of momentum and the continuity equation for the conservation of mass are solved for laminar flow. Piecewise linear interpolation is considered for velocity and pressure in laminar flow discretization. Convection-diffusion heat transfer equation is used by the heat transfer module. The 2D models are created using the geometry module available in COMSOL Multiphysics. The ambient temperature is taken as $30^{\circ} \mathrm{C}$ for all the cases of simulation. 
The incoming solar direct normal insolation $\left(\mathrm{I}_{\mathrm{r}}\right)$ is taken as $1000 \mathrm{~W} / \mathrm{m}^{2}$ in all the cases.

The orientation angle of the receiver is chosen as $0^{\circ}$ to $90^{\circ}$ with a step size of $15^{\circ}$.

199 Totally, 35 combinations of simulations are conducted for each receiver types. The boundary conditions for the receiver are: the outer walls of the receivers are considered as well insulated, the cavity temperature which is mentioned above represents the exposed area of the receiver to the concentrated flux from the concentrator.

Whereas, the walls of the air domain are considered as the open boundary where, both mass and energy interactions are possible.

204 The next step is to provide proper meshing to the geometrical model. Grid independence test is carried out and 205 the results are shown in Table 2. Finally, physics-based meshing with boundary refinements are carried out for 206 better results. The independence test is carried out for modified conical cavity receiver, for a cavity temperature 207 of $400^{\circ} \mathrm{C}$ and $0^{\circ}$ orientation. The maximum element size is varied from $0.012 \mathrm{~m}$ to $0.018 \mathrm{~m}$, from which the 208 overall heal loss coefficient is found the value doesn't change significantly. Hence, the middle value is taken as 209 the common for all simulations.

210 Table 2 Grid Independence test for modified conical cavity receiver at the cavity temperature of $400^{\circ} \mathrm{C}$ and $0^{\circ}$ 211 orientation

\begin{tabular}{lrrrrrrr}
\hline E_max (m) & 0.012 & 0.013 & 0.014 & 0.015 & 0.0160 & 0.017 & 0.018 \\
E_min (m) & 0.00015 & 0.00015 & 0.00015 & 0.00015 & 0.00015 & 0.00015 & 0.00015 \\
No. of elements & 29965 & 29408 & 28858 & 28237 & 28025 & 27612 & 27102 \\
Overall heat loss coefficient & & & & & & & \\
$\left(\mathrm{U}_{\mathrm{L}}\right)\left(\mathrm{W} / \mathrm{m}^{2} \mathrm{~K}\right)$ & 18.8723 & 18.8369 & 18.8013 & 18.8607 & 18.8292 & 18.8846 & 18.8338
\end{tabular}

212

213 2.5. Model Validation

214 The developed model is validated with the previous literature numerical results from the work of Reddy et 215 al.(Sendhil Kumar and Reddy 2007a) and shown in figure 2. 


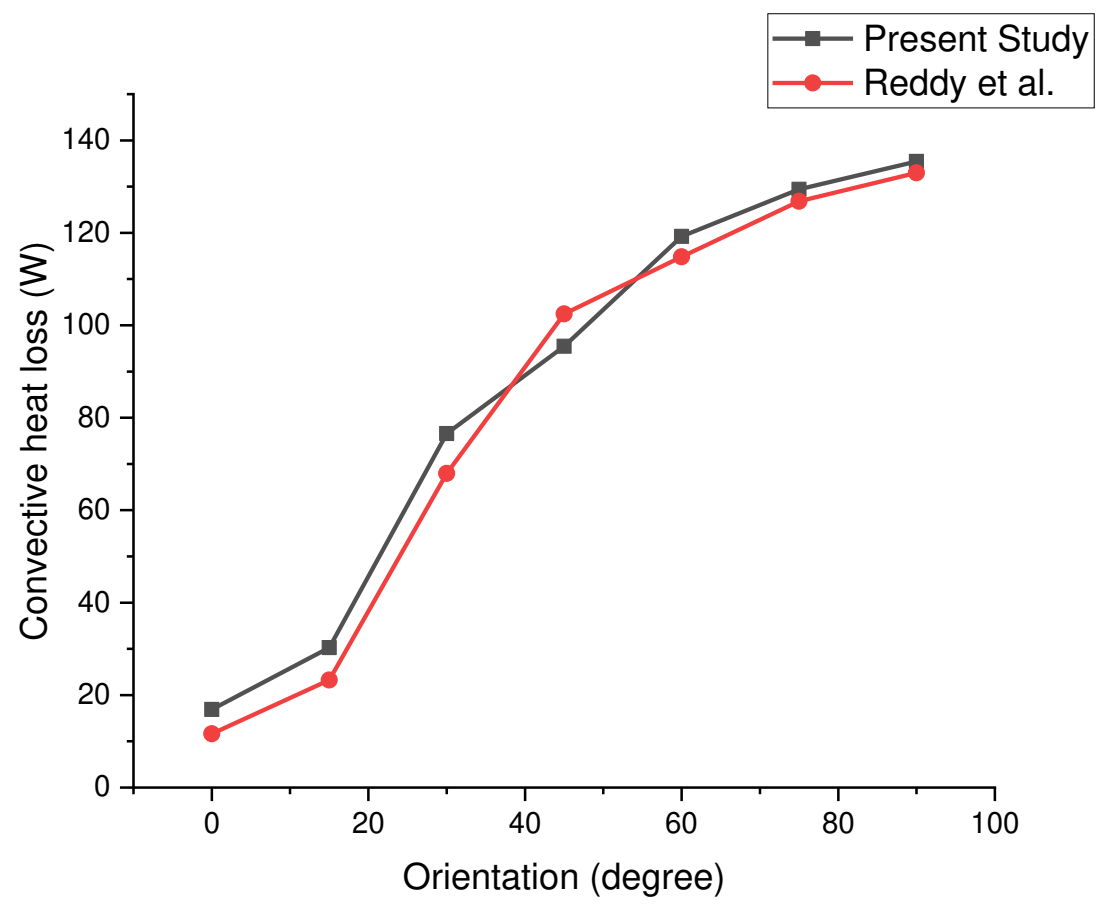

217 Figure 2 Comparison of convective heat loss in modified cavity receiver from present study and Reddy's work

218 In the current study, the orientations such as $0,15,30,45,60,75$ and 90 are having lower deviations of convective

219 heat loss when compared to the Reddy et al. model. The deviation of convective heat loss between the present

220 model and Reddy model varies from $2.44 \mathrm{~W}$ to $8.6 \mathrm{~W}$. From the validation report it is observed that the convective

221 heat loss has good agreement with the existing work at the inclinations ranges from $0^{\circ}$ to $90^{\circ}$. Hence, the present

222 model is considered as validated with the existing research work(Sendhil Kumar and Reddy 2007a).

\section{3. Results \& Discussions}

\section{3.1 Ray-Tracing results}

225 The results of the ray-tracing analysis for the given parabolic dish concentrator are shown in figure 3 and figure

226 4. Figure 3(a) illustrates the reflected ray propagation from the dish. Figure 3(b) illustrates the deposited ray 227 distribution on the focal plane of the given concentrator. The power distribution at the mid of the focal plane is 228 found to be highest and it diminishes as moving towards outside. The total power deposited on the focal plane is 229 found to be $10,958 \mathrm{~W}$ and hence, the concentrator optical efficiency $\left(\eta_{\text {con }}\right)$ is calculated as 87.4 per cent. 


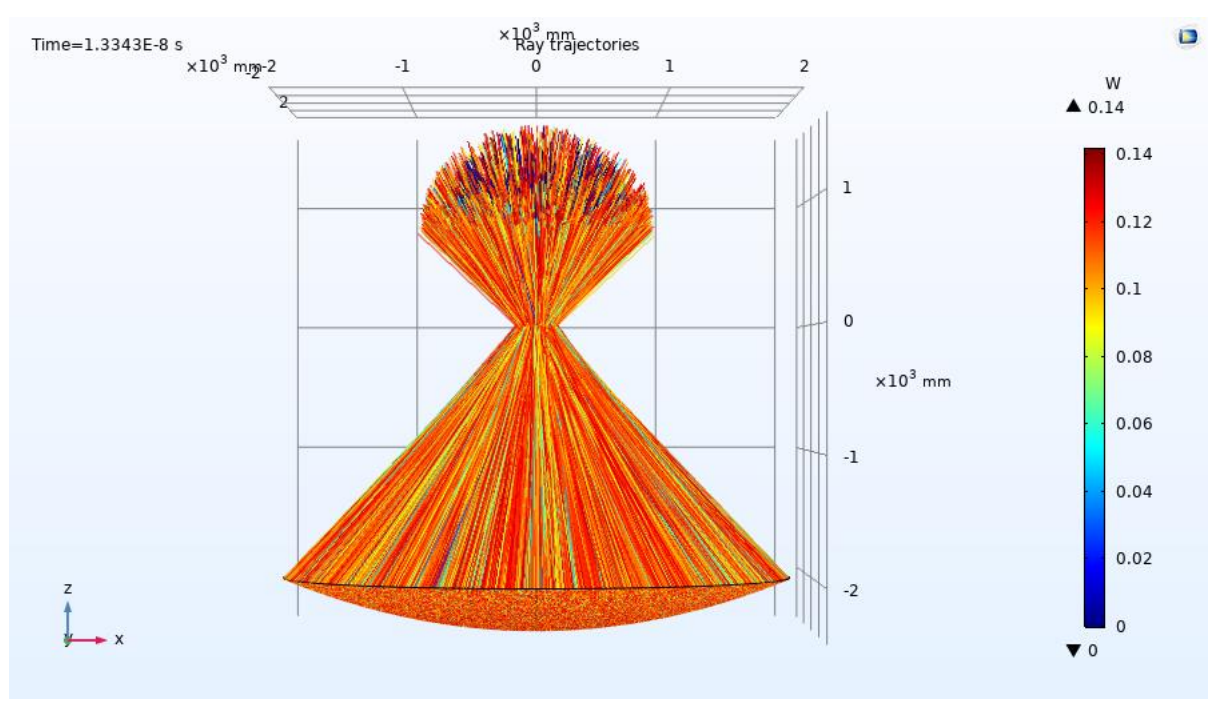

(a)

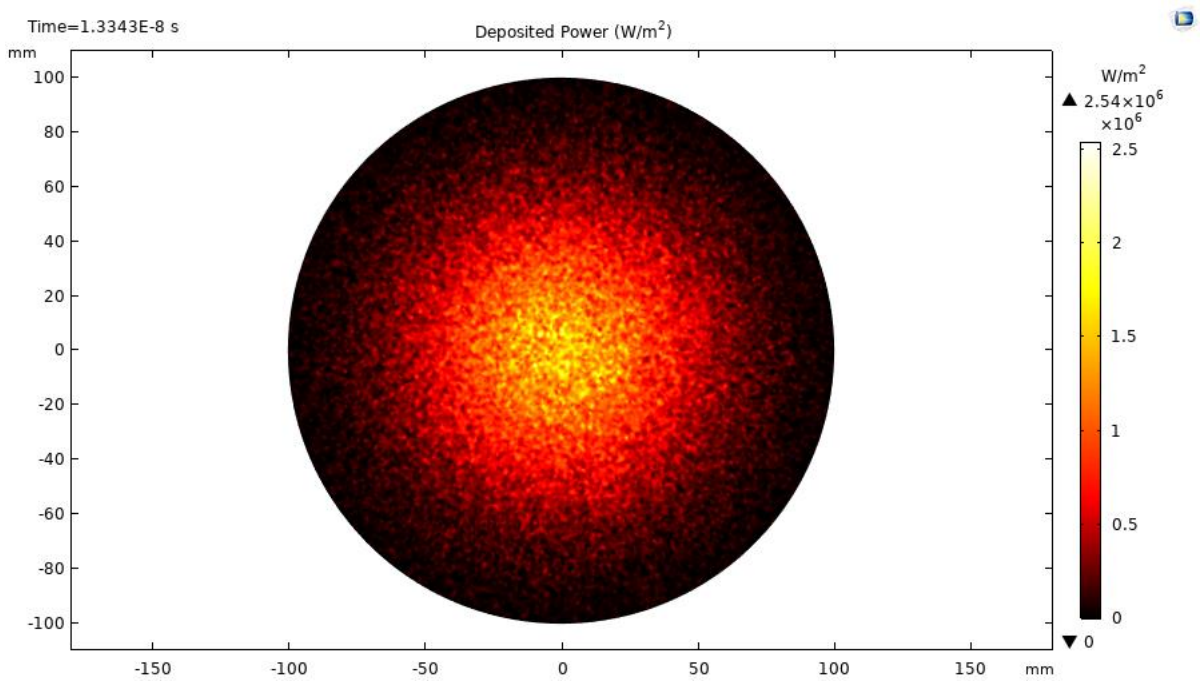

(b)

230 Figure 3 Illustration of (a) the propagation of reflected rays from the parabolic dish concentrator (b) the flux 231 distribution over the focal plane

232 Figure 4 graphically depicts the radial distribution of the concentration ratio along the focal plane. From the graph 233 it is observed that the concentration ratio peaks at the mid and gradually decreases as moving towards the outer 234 edge. Nullifying the effect of concentration ratio below 100, the solar image size is determined as $160 \mathrm{~mm}$ with reference to the graph. This same dimension is kept as the aperture diameter for all the receivers which are compared in the current study. In case of modified cavity receiver and modified conical receivers, the opening diameter is taken as $60 \mathrm{~mm}$ where the concentration ratios are above 1000. 


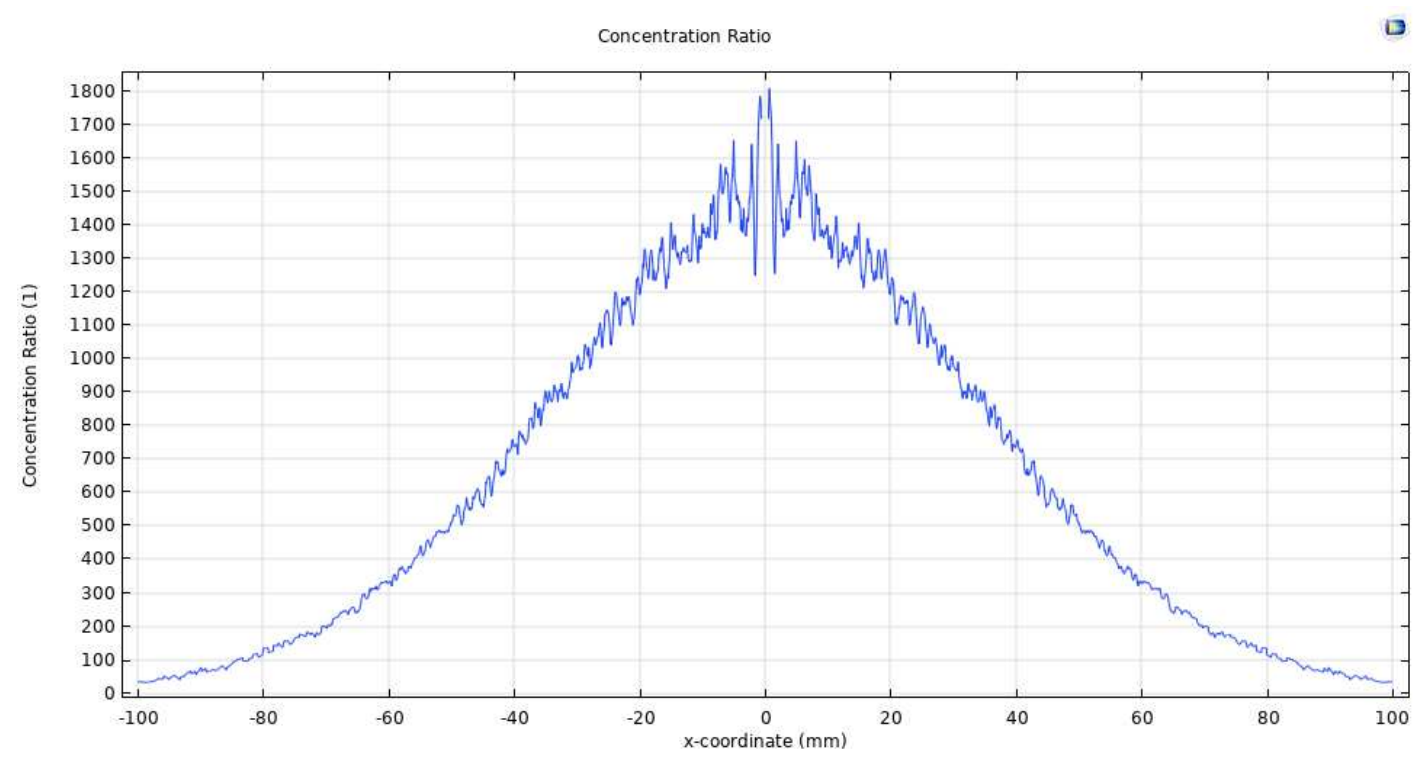

Figure 4 Graphical representation of radial distribution of concentration ratio over the focal plane

\section{mparison of Receivers \\ $240 \quad 3.2$ Comparison of Receivers}

241 The second part of the work is comparison of the receivers. Figure 5(a), 5(b), 5(c) and 5(d) shows the temperature

242 contour of the cylindrical, conical, modified cavity and modified conical cavity receivers at $400^{\circ} \mathrm{C}$ cavity

243 temperatures and various orientations.
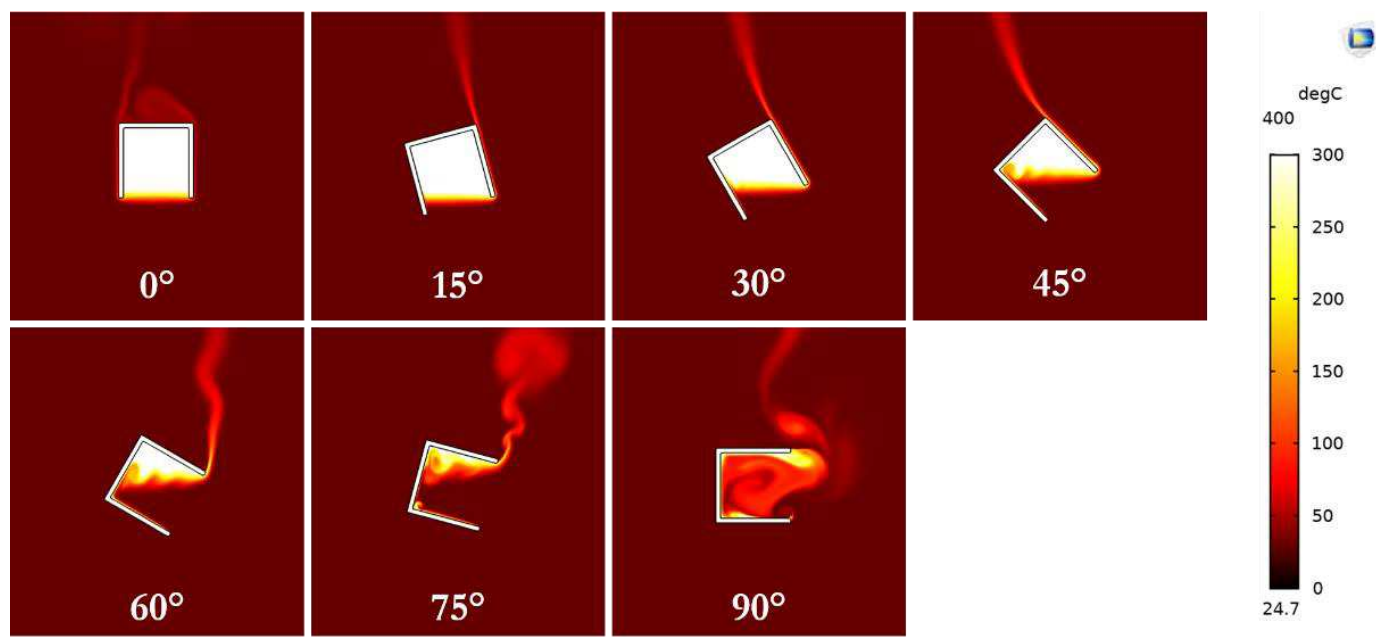

(a) 


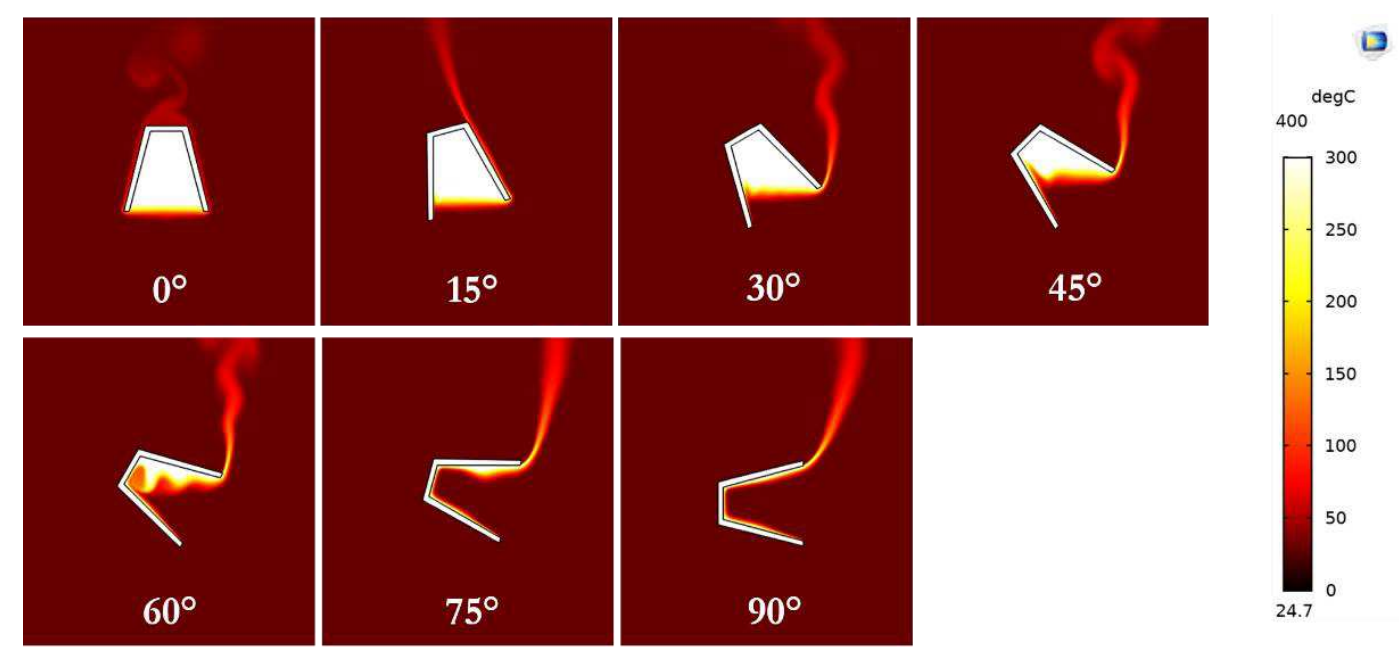

(b)
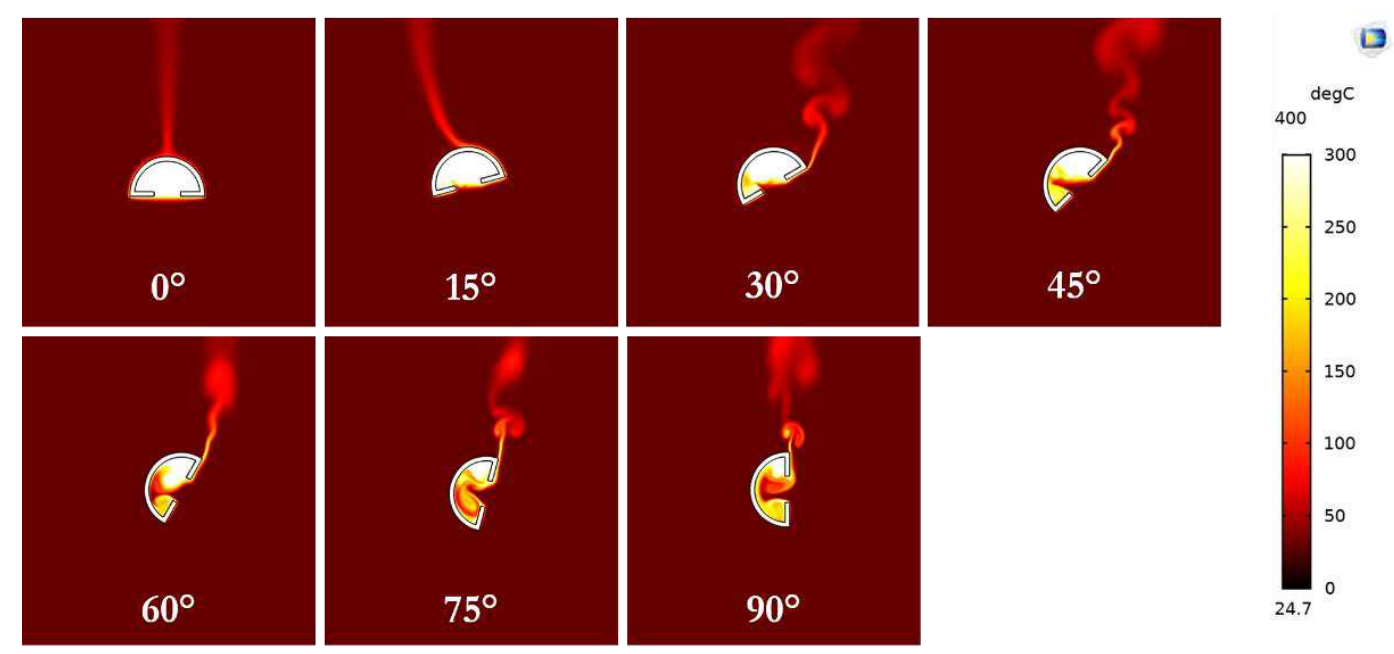

(c)
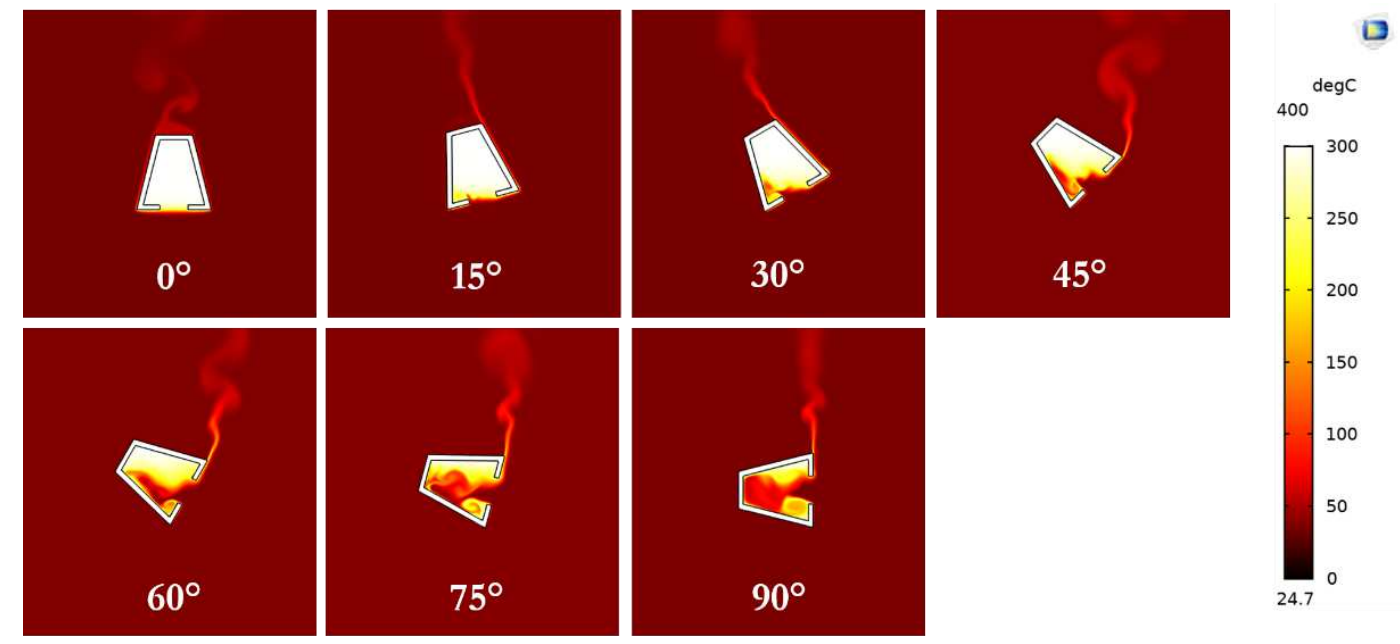

(d) 
245 Figure 5 Temperature contour of (a) cylindrical cavity receiver (b) conical cavity receiver (c) modified cavity

246 receiver and (d) modified conical cavity receiver at various orientations for $400^{\circ} \mathrm{C}$.

247 From the figure 5, it is observed that the stagnation zone is more at $0^{\circ}$ orientation and the stagnation zone gets

248 degraded as the orientation approaches towards $90^{\circ}$. This is because of the fact that as the air is heated, the density

249 of air reduces as a result of it, the hot air tends to move towards upward. In case of $0^{\circ}$ orientation the flow of air

250 against gravity is arrested by the walls of the receiver. Whereas, in case of other orientations, the hot air get space

251 to escape out of the receiver. The convective heat loss is higher in the case of lower stagnation zone. Since radiation is a temperature phenomenon, the radiative heat loss remains the same for all orientations and it depends

253 on the cavity temperature.

254 The conductive heat loss is not considered for the analysis since the value is negligible when compared to the 255 convective and radiative heat losses. The convective and radiative heat losses are considered for the analysis. The 256 total heat losses through the aperture of each cavity receiver configurations are calculated and obtained from the 257 numerical results. The figure 6 illustrates the variation of total heat losses from the receivers with respect to change 258 in temperature as well as orientation. From the results it is observed that the cavity receivers can be sorted as 259 cylindrical cavity, conical cavity, modified cavity and modified conical cavity receiver respectively with respect 260 to the total heat loss. Modified conical cavity receiver is claimed to be better among the four compared receivers 261 and modified cavity receiver is found to be the best next to the modified conical followed by conical cavity receiver and cylindrical cavity receiver. Also, it is found that the heat loss increases exponentially in case of cylindrical and conical cavity receivers whereas, for the modified conical cavity receivers, the temperature varies almost linearly with respect to the temperature. 


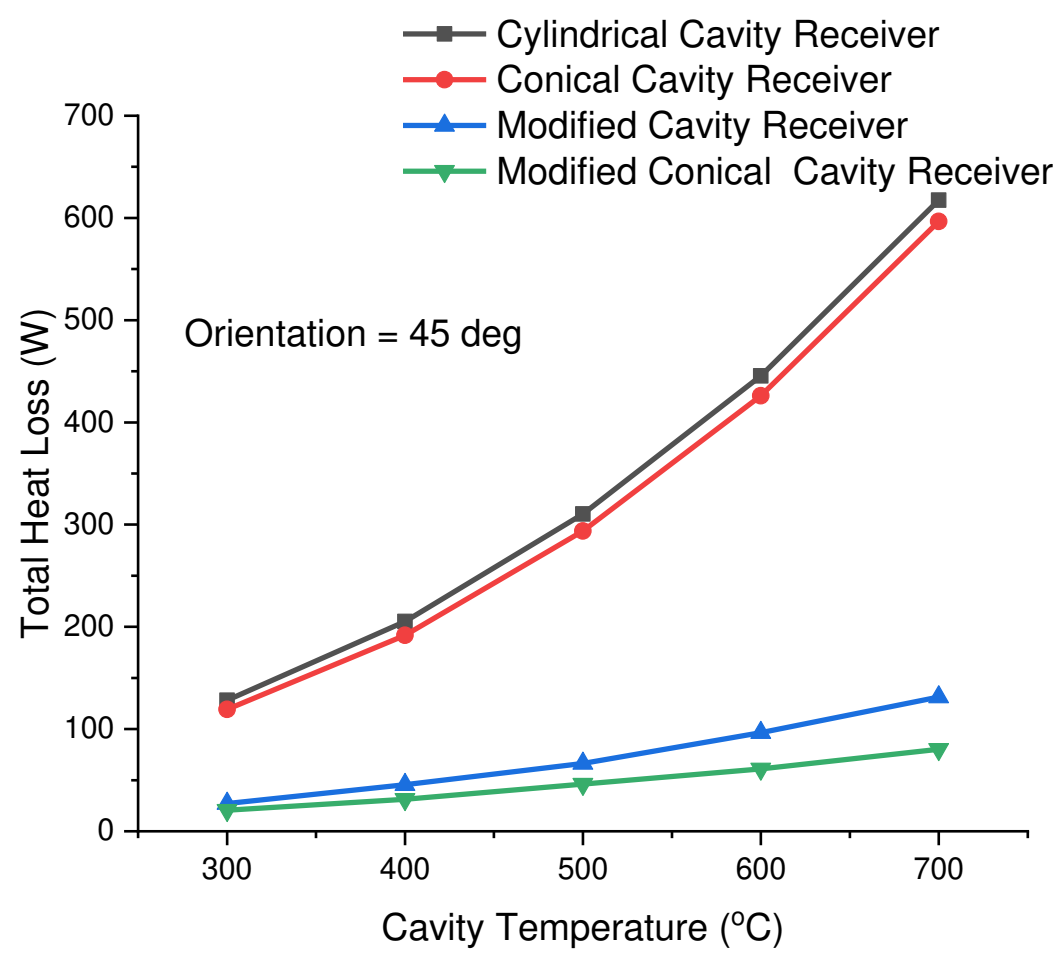

(a)

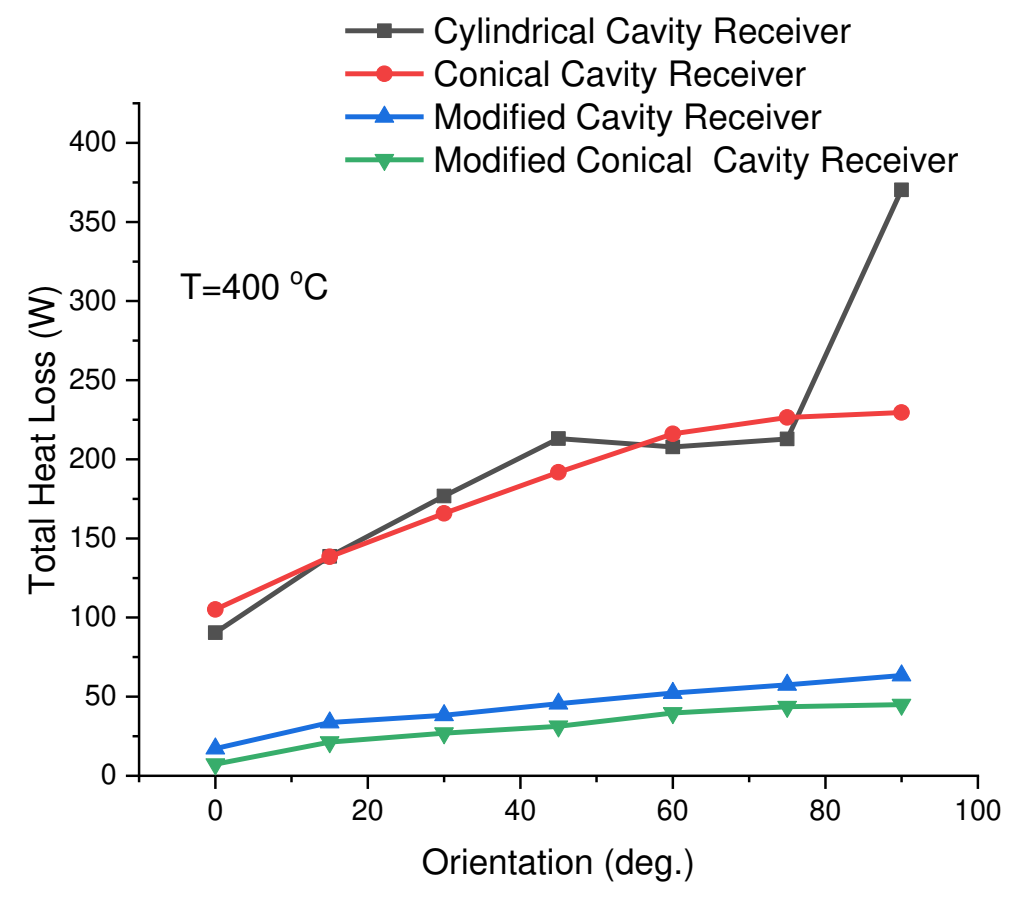

(b)

265 Figure 6 Variation of total heat loss from the various cavity receivers (a) with respect to cavity temperature for $26645^{\circ}$ orientation and (b) with respect to receiver orientation for $400^{\circ} \mathrm{C}$ cavity temperature. 
267 As per the simulation results the modified conical cavity and modified cavity receivers are found to be the better 268 designs and hence for the clear understanding of the heat loss variations at various cavity temperatures and 269 orientations, the graphical illustration is given for both modified cavity and modified conical cavity receivers in 270 figure 7. The dotted line represents the modified cavity and the continuous line represents the modified conical cavity receiver. It clearly depicts that the difference of heat loss between modified conical and modified receiver increases gradually with respect to the cavity temperature. Hence modified conical cavity receiver is found to be better design than the other compared receivers.

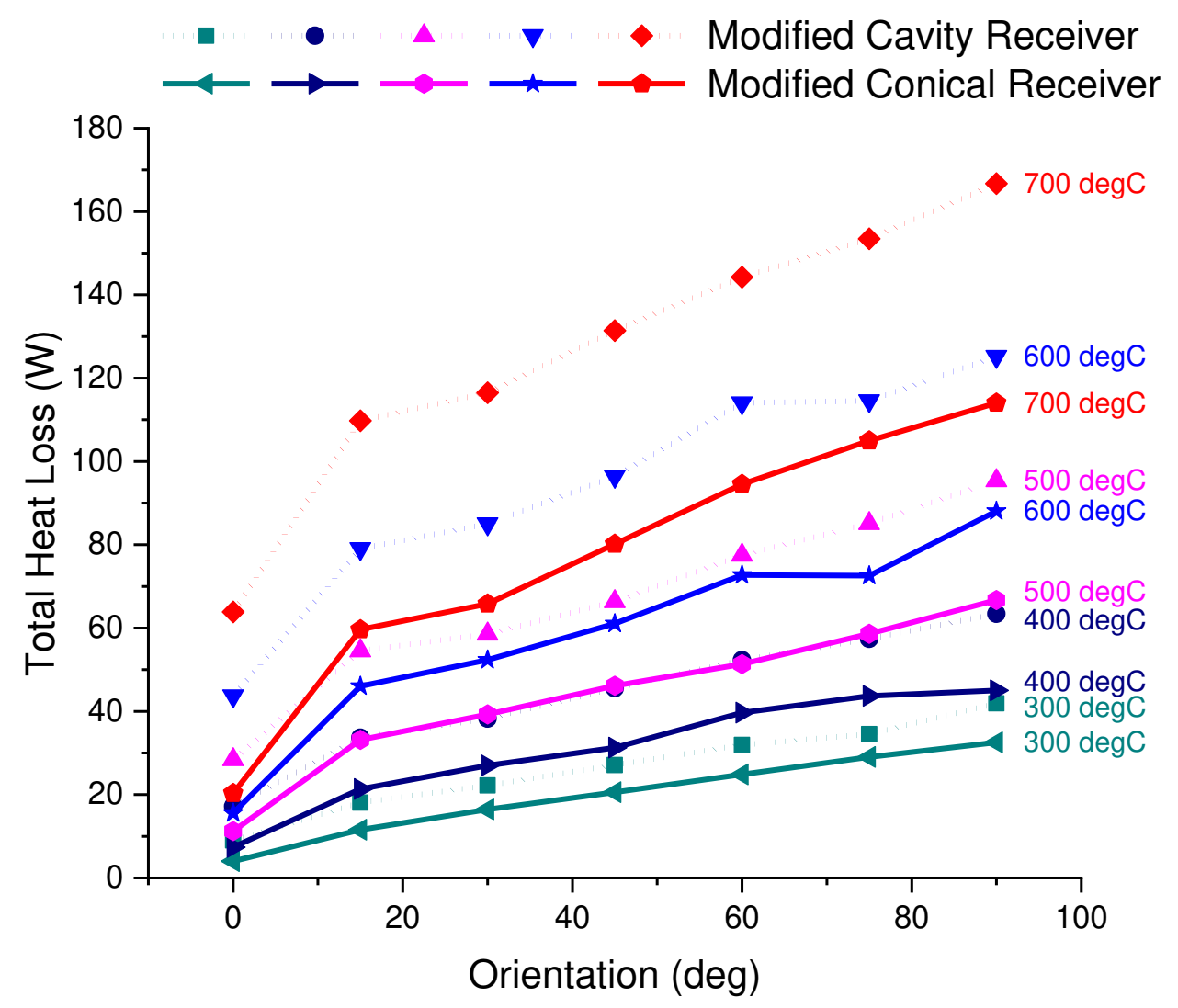

Figure 7 Illustrates the variation of total heat loss of the modified and modified conical cavity receivers for various orientations and temperatures.

\section{Conclusion}

277 Solar parabolic dish concentrator emerged as one of the best solar energy utilization technique. In which the cavity receiver design plays a major role in improving the efficiency of the system by reducing the heat losses. In this work, a novel cavity receiver, modified conical cavity receiver is proposed and it is numerically compared with other receivers such as cylindrical, conical and modified cavity receivers by conducting heat transfer coupled with laminar flow problem using COMSOL Multiphysics. Based on the numerical results following findings are found: It is found that the modified conical cavity receiver is the most efficient followed by modified cavity, conical and 
cylindrical cavity receivers. The solar thermal conversion efficiency criterion at $400^{\circ} \mathrm{C}$, the modified conical receiver is found to be $84.7 \%$, whereas, for other receivers such as modified cavity, conical and cylindrical cavity, the efficiencies are $83.5 \%, 71.5 \%$ and $67.3 \%$ respectively.

286 Declarations:

287 Ethics approval and consent to participate: Not applicable

288 Consent for Publication: Not applicable

289 Availability of data and materials: The datasets used and/or analysed during the current study are available 290 from the corresponding author on reasonable request

291 Competing interests: The authors declare that they have no competing interests.

292 Funding: Not applicable

\section{Author Contributions - Credit author statement}

294 Arjun Singh K: Conceptualization, Formal analysis, Investigation, Data Curation, Writing - Original Draft.

295 Sendhil Kumar Natarajan: Conceptualization, Validation, Resources, Writing - Review \& Editing, Supervision, 296 Project administration.

\section{Acknowledgement}

298 The authors would like to gratefully acknowledge for all the supports provided by the National Institute of Technology Puducherry, Karaikal.

300

References

302

Arrif T, Benchabane A, Chehhat A, et al (2018) Numerical simulation of convective heat losses in a helical tube of a cylindrical solar receiver Simulation numérique des pertes thermiques par convection dans un tube hélicoïdal d ' un récepteur solaire cylindrique. J Appl Eng Sci Technol 4:177-187 (PTC) efficiency improvement. Renew Energy 31:2411-2421. 
Barker L, Neber M, Lee H (2013) Design of a low-profile two-axis solar tracker. Sol Energy 97:569-576. https://doi.org/10.1016/j.solener.2013.09.014

Chong KK, Wong CW (2009) General formula for on-axis sun-tracking system and its application in improving tracking accuracy of solar collector. Sol Energy 83:298-305. https://doi.org/10.1016/j.solener.2008.08.003

Coventry J, Andraka C (2017) Dish systems for CSP. Sol Energy 152:140-170. https://doi.org/10.1016/j.solener.2017.02.056

Daabo AM, Mahmoud S, Al-Dadah RK (2016) The effect of receiver geometry on the optical performance of a small-scale solar cavity receiver for parabolic dish applications. Energy 114:513-525. https://doi.org/10.1016/j.energy.2016.08.025

Hafez AZ, Soliman A, El-Metwally KA, Ismail IM (2017) Design analysis factors and specifications of solar dish technologies for different systems and applications. Renew Sustain Energy Rev 67:1019-1036. https://doi.org/10.1016/j.rser.2016.09.077

Hijazi H, Mokhiamar O, Elsamni O (2016) Mechanical design of a low cost parabolic solar dish concentrator. Alexandria Eng J 55:1-11. https://doi.org/10.1016/j.aej.2016.01.028

Jilte RD, Kedare SB, Nayak JK (2014) Investigation on convective heat losses from solar cavities under wind conditions. Energy Procedia 57:437-446. https://doi.org/10.1016/j.egypro.2014.10.197

John AG, J. NM (2015) Design and Simulation of Parabolic Dish Collector for Hot Water Generation. Int J Curr Eng Sci Res 2:20-24

Kaushika ND (1993) Viability aspects of paraboloidal dish solar collector systems. Renew Energy 3:787-793

Kaushika ND, Reddy KS (2000) Performance of a low cost solar paraboloidal dish steam generating system. Energy Convers Manag 41:713-726. https://doi.org/10.1016/S0196-8904(99)00133-8

Li L, Dubowsky S (2011) A new design approach for solar concentrating parabolic dish based on optimized flexible petals. Mech Mach Theory 46:1536-1548. https://doi.org/10.1016/j.mechmachtheory.2011.04.012

Li X, Dai YJ, Wang RZ (2015a) Performance investigation on solar thermal conversion of a conical cavity receiver employing a beam-down solar tower concentrator. Sol Energy 114:134-151. https://doi.org/10.1016/j.solener.2015.01.033

Li Y, Liu G, Rao Z, Liao S (2015b) Field synergy principle analysis for reducing natural convection heat loss of 
Loni R, Askari Asli-Ardeh E, Ghobadian B, et al (2018a) Thermal performance comparison between A12O3/oil and $\mathrm{SiO} 2 /$ oil nanofluids in cylindrical cavity receiver based on experimental study. Renew Energy 129:652-665. https://doi.org/10.1016/j.renene.2018.06.029

Loni R, Kasaeian AB, Askari Asli-Ardeh E, et al (2018b) Experimental and numerical study on dish concentrator with cubical and cylindrical cavity receivers using thermal oil. Energy 154:168-181. https://doi.org/10.1016/j.energy.2018.04.102

Lovegrove K, Zawadski A, Coventy J (2003) Paraboloidal Dish Solar Concentrators for Multi-Megawatt Power Generation. Proc ISES 14-19

Mancini T, Heller P, Butler B, et al (2003) Dish-Stirling Systems: An Overview of Development and Status. J Sol Energy Eng 125:135. https://doi.org/10.1115/1.1562634

Melchior T, Perkins C, Weimer AW, Steinfeld A (2008) A cavity-receiver containing a tubular absorber for high-temperature thermochemical processing using concentrated solar energy. Int J Therm Sci 47:14961503. https://doi.org/10.1016/j.ijthermalsci.2007.12.003

Ngo LC, Bello-Ochende T, Meyer JP (2015a) Three-dimensional analysis and numerical optimization of combined natural convection and radiation heat loss in solar cavity receiver with plate fins insert. Energy Convers Manag 101:757-766. https://doi.org/10.1016/j.enconman.2015.05.061

Nsengiyumva W, Chen SG, Hu L, Chen X (2018) Recent advancements and challenges in Solar Tracking

Ngo LC, Bello-Ochende T, Meyer JP (2015b) Numerical modelling and optimisation of natural convection heat Systems (STS): A review. Renew Sustain Energy Rev 81:250-279. https://doi.org/10.1016/j.rser.2017.06.085

Prakash M, Kedare SB, Nayak JK (2009) Investigations on heat losses from a solar cavity receiver. Sol Energy 83:157-170. https://doi.org/10.1016/j.solener.2008.07.011

Prakash M, Kedare SB, Nayak JK (2010) Determination of stagnation and convective zones in a solar cavity receiver. Int J Therm Sci 49:680-691. https://doi.org/10.1016/j.ijthermalsci.2009.06.015 
receiver with fuzzy focal solar dish concentrator. Renew Energy 74:148-157. https://doi.org/10.1016/j.renene.2014.07.058

Reddy KS, Natarajan SK, Veershetty G (2015b) Experimental performance investigation of modified cavity receiver with fuzzy focal solar dish concentrator. Renew Energy 74:148-157. https://doi.org/10.1016/j.renene.2014.07.058

Reddy KS, Sendhil Kumar N (2008) Combined laminar natural convection and surface radiation heat transfer in a modified cavity receiver of solar parabolic dish. Int J Therm Sci 47:1647-1657. https://doi.org/10.1016/j.ijthermalsci.2007.12.001

Reddy KS, Sendhil Kumar N (2009) An improved model for natural convection heat loss from modified cavity receiver of solar dish concentrator. Sol Energy 83:1884-1892. https://doi.org/10.1016/j.solener.2009.07.001

Reddy KS, Veershetty G, Srihari Vikram T (2016) Effect of wind speed and direction on convective heat losses from solar parabolic dish modified cavity receiver. Sol Energy 131:183-198. https://doi.org/10.1016/j.solener.2016.02.039

Reddy KS, Vikram TS, Veershetty G (2015c) Combined heat loss analysis of solar parabolic dish - Modified cavity receiver for superheated steam generation. Sol Energy. https://doi.org/10.1016/j.solener.2015.04.028

Reddy KS, Vikram TS, Veershetty G (2015d) Combined heat loss analysis of solar parabolic dish - Modified cavity receiver for superheated steam generation. Sol Energy 121:78-93. https://doi.org/10.1016/j.solener.2015.04.028

Sahu SK, K AS, Natarajan SK (2020) Design and development of a low-cost solar parabolic dish concentrator system with manual dual-axis tracking. Int J Energy Res 1-11. https://doi.org/10.1002/er.6164

Sendhil Kumar N, Reddy KS (2007a) Numerical investigation of natural convection heat loss in modified cavity

Sendhil Kumar N, Reddy KS (2007b) Numerical investigation of natural convection heat loss in modified cavity characteristics of a spherical cavity receiver. Appl Therm Eng. https://doi.org/10.1016/j.applthermaleng.2018.10.030 
Soltani S, Bonyadi M, Madadi Avargani V (2019) A novel optical-thermal modeling of a parabolic dish collector with a helically baffled cylindrical cavity receiver. Energy 168:88-98. https://doi.org/10.1016/j.energy.2018.11.097

Srithar K, Rajaseenivasan T, Karthik N, et al (2016) Stand alone triple basin solar desalination system with cover cooling and parabolic dish concentrator. Renew Energy 90:157-165. https://doi.org/10.1016/j.renene.2015.12.063

Sup BA, Zainudin MF, ZanariahShamsirAli T, et al (2015) Effect of rim angle to the flux distribution diameter in solar parabolic dish collector. Energy Procedia 68:45-52. https://doi.org/10.1016/j.egypro.2015.03.231

Thirugnanasambandam M, Iniyan S, Goic R (2010) A review of solar thermal technologies. Renew Sustain Energy Rev 14:312-322. https://doi.org/10.1016/j.rser.2009.07.014

Vikram TS, Reddy KS (2015) Investigation of convective and radiative heat losses from modified cavity based solar dish steam generator using ANN. Int J Therm Sci 87:19-30. https://doi.org/10.1016/j.ijthermalsci.2014.08.005

Vikram TS, Reddy KS (2014) Estimation of heat losses from modified cavity mono-tube boiler receiver of solar parabolic dish for steam generation. Energy Procedia 57:371-380. https://doi.org/10.1016/j.egypro.2014.10.190

Wang F, Lin R, Liu B, et al (2013) Optical efficiency analysis of cylindrical cavity receiver with bottom surface convex. Sol Energy 90:195-204. https://doi.org/10.1016/j.solener.2013.01.017

Wang J, Yang S, Jiang C, et al (2017) A novel 2-stage dish concentrator with improved optical performance for concentrating solar power plants. Renew Energy 108:92-97. https://doi.org/10.1016/j.renene.2017.02.059

Wu SY, Xiao L, Cao Y, Li YR (2010) Convection heat loss from cavity receiver in parabolic dish solar thermal power system: A review. Sol Energy 84:1342-1355. https://doi.org/10.1016/j.solener.2010.04.008

Yan J, Peng Y duo, Cheng Z ran (2018) Optimization of a discrete dish concentrator for uniform flux distribution on the cavity receiver of solar concentrator system. Renew Energy. https://doi.org/10.1016/j.renene.2018.06.025

Yang S, Wang J, Lund PD, et al (2018a) Design and performance evaluation of a high-temperature cavity receiver for a 2-stage dish concentrator. Sol Energy 174:1126-1132. https://doi.org/10.1016/j.solener.2018.10.021

Yang S, Wang J, Lund PD, et al (2018b) Reducing convective heat losses in solar dish cavity receivers through a modified air-curtain system. Sol Energy 166:50-58. https://doi.org/10.1016/j.solener.2018.03.027 
Figures

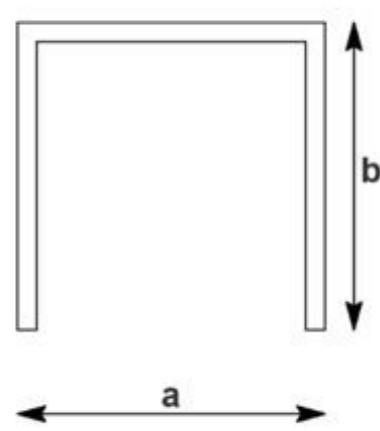

(A)

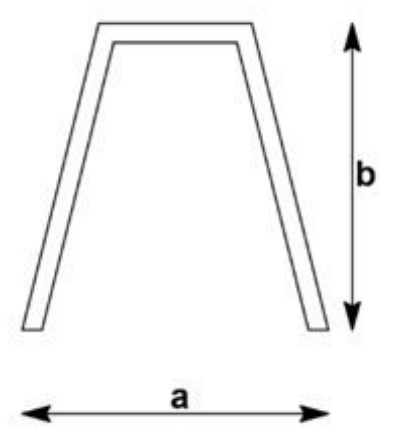

(B)

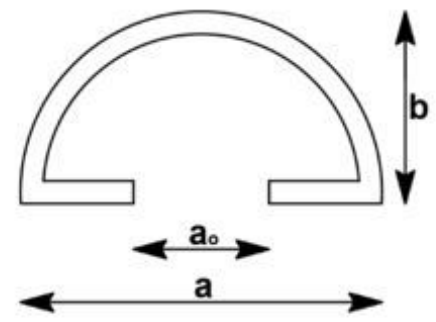

(C)

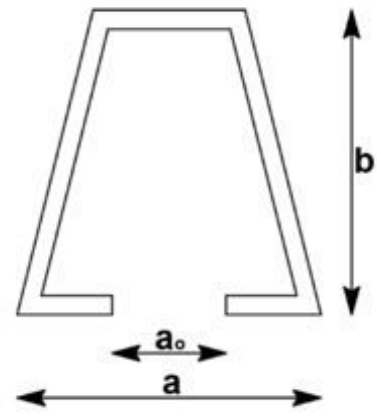

(D)

Figure 1

Cavity receivers used for the study (A) Cylindrical (B) Conical (C) Modified (D) Modified Conical Cavity Receivers

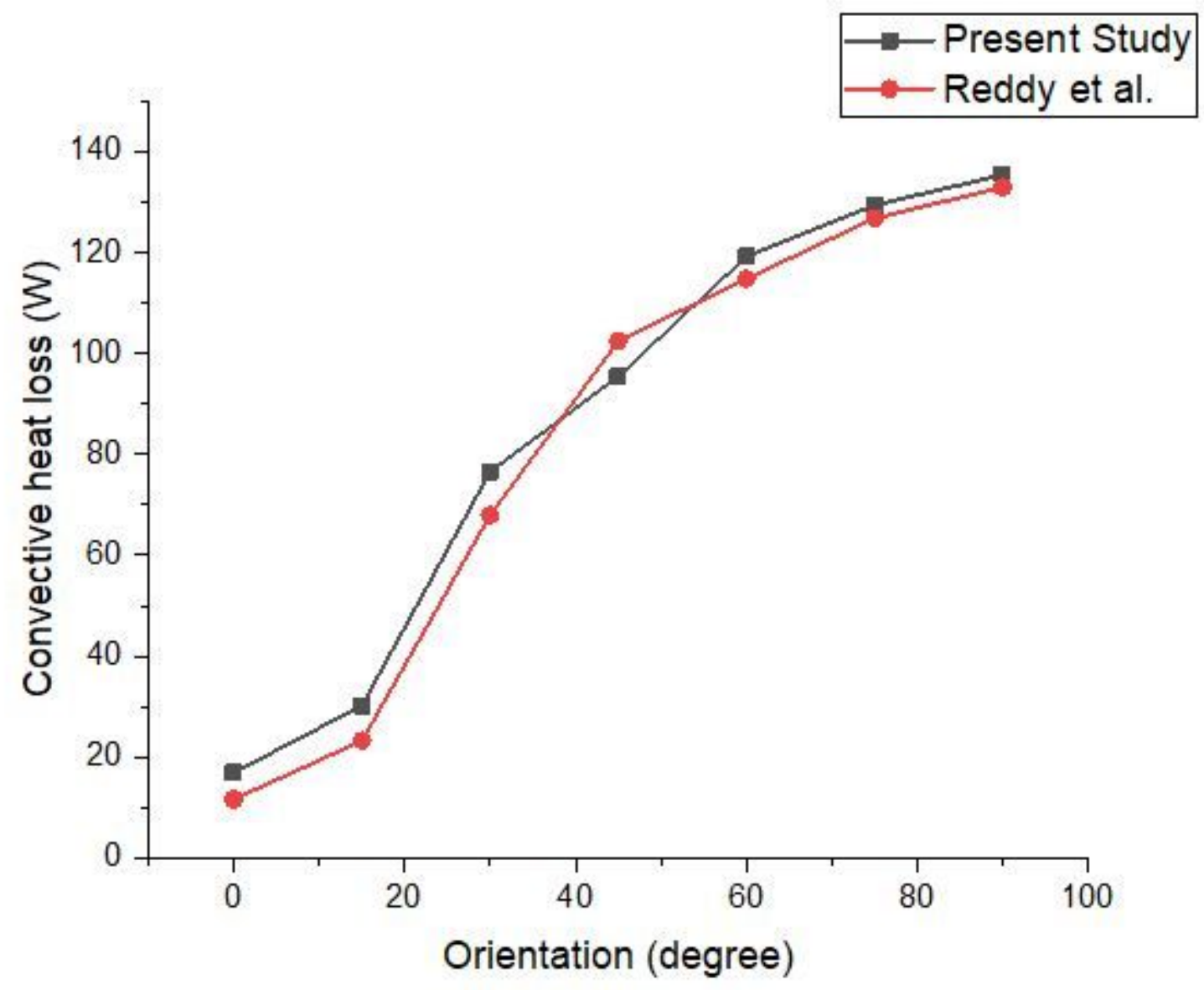


Figure 2

Comparison of convective heat loss in modified cavity receiver from present study and Reddy's work

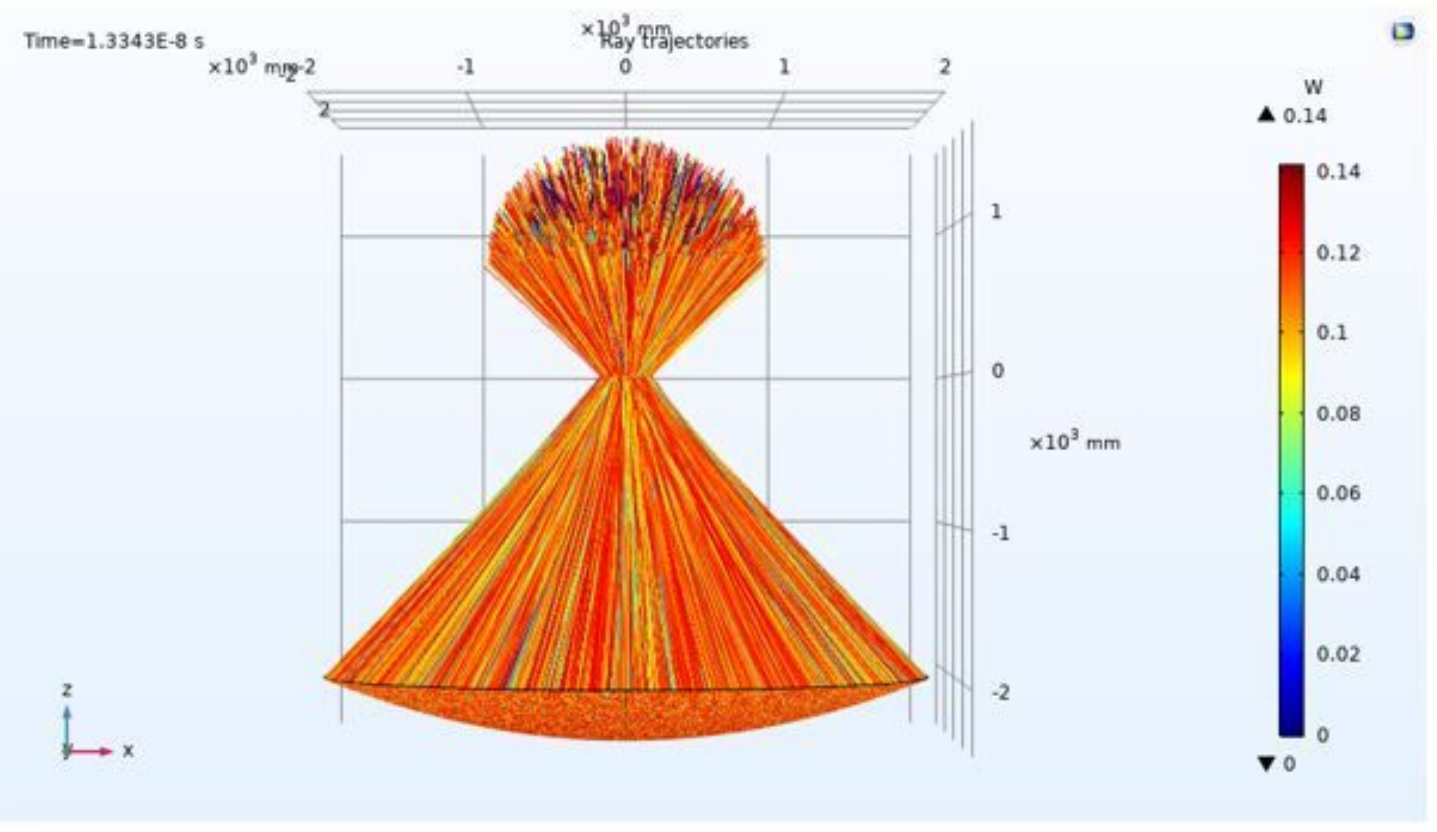

(a)

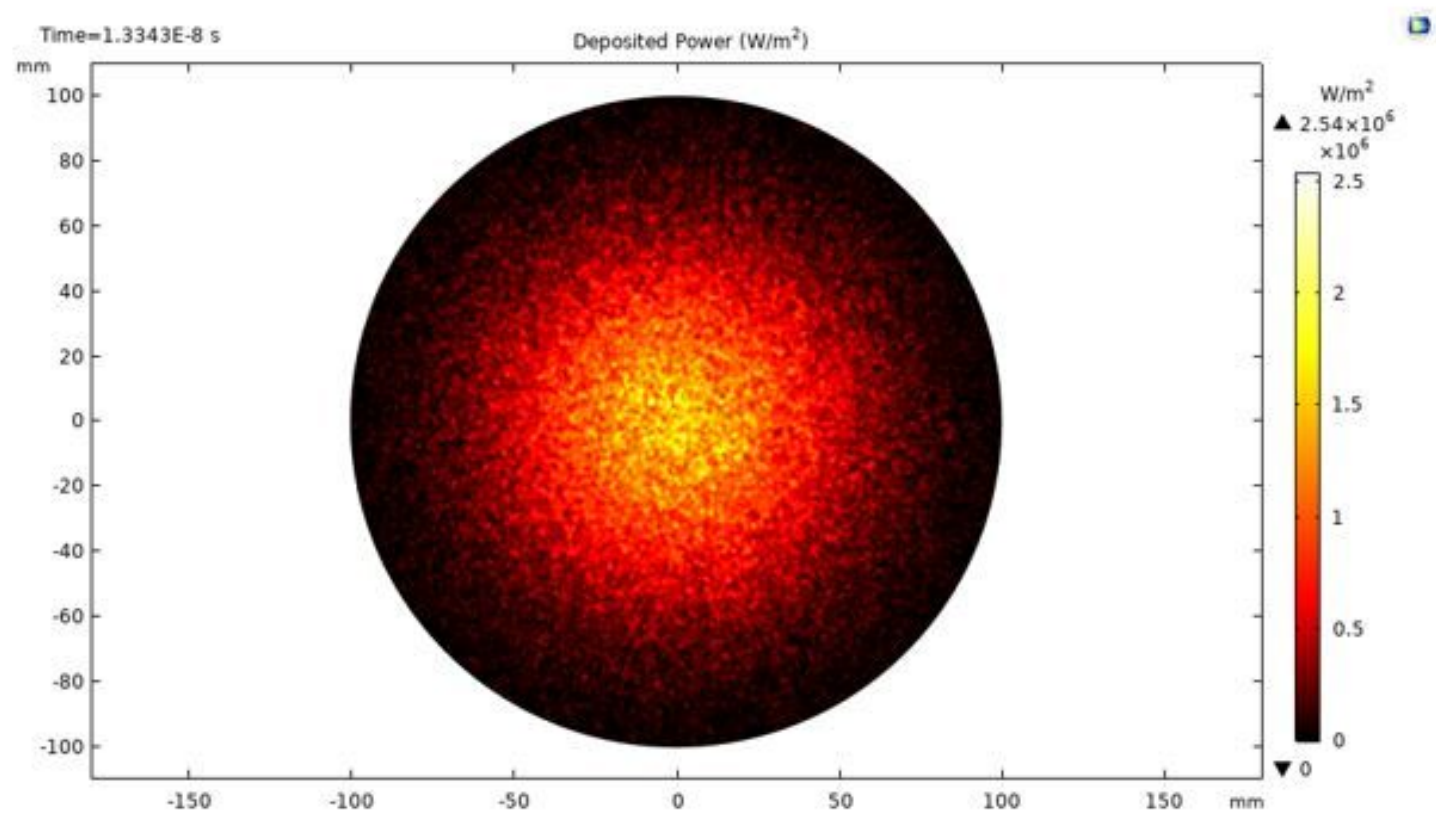

(b)

\section{Figure 3}

Illustration of (a) the propagation of reflected rays from the parabolic dish concentrator (b) the flux distribution over the focal plane 


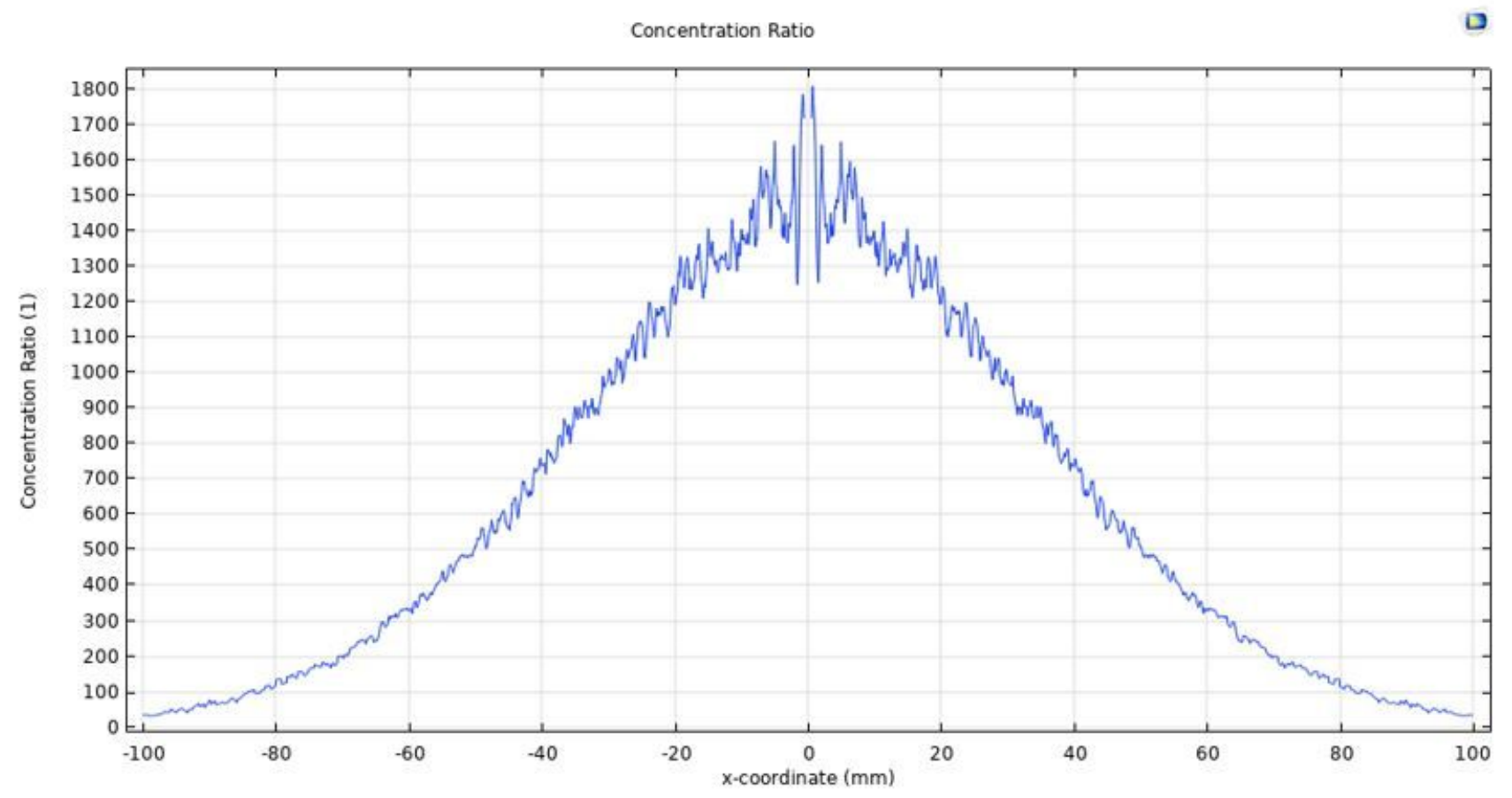

Figure 4

Graphical representation of radial distribution of concentration ratio over the focal plane 


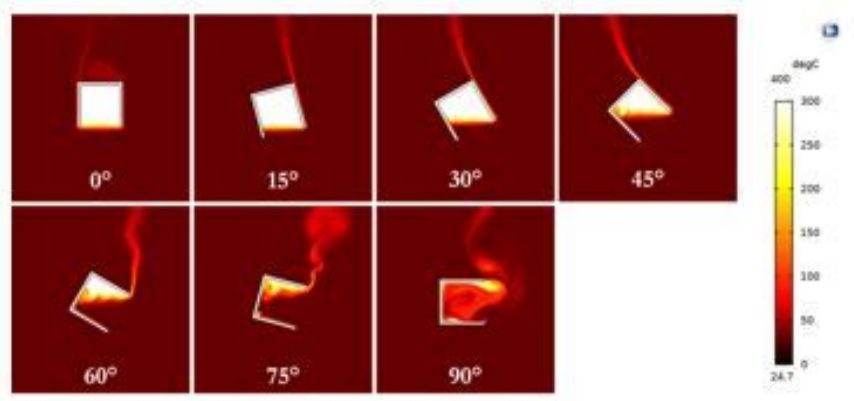

(a)

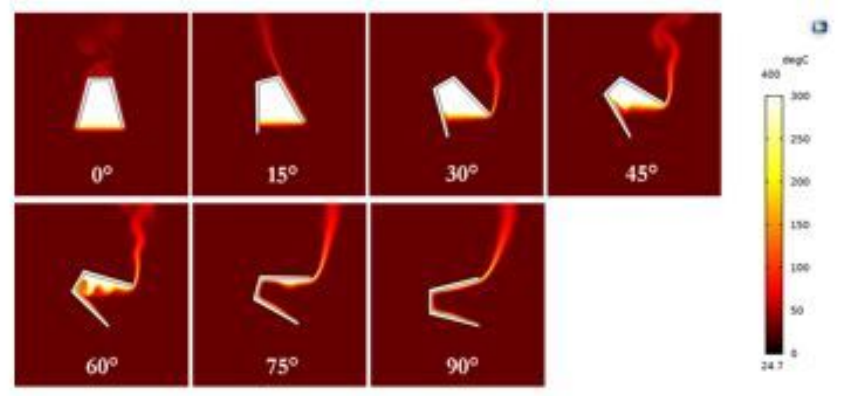

(b)

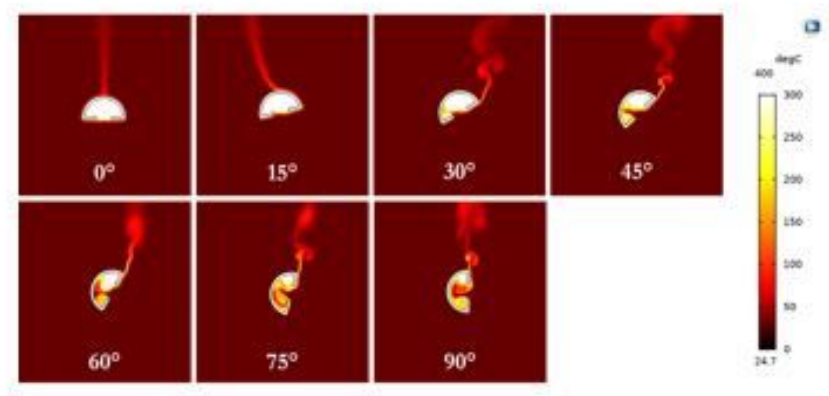

(c)

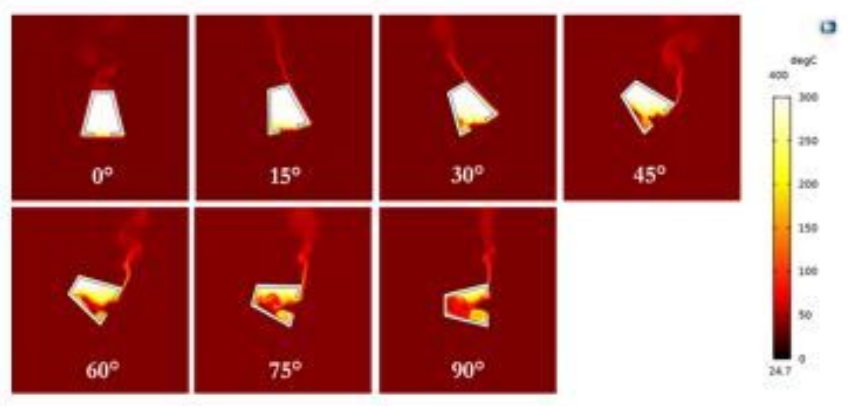

(d)

Figure 5

Temperature contour of (a) cylindrical cavity receiver (b) conical cavity receiver (c) modified cavity receiver and (d) modified conical cavity receiver at various orientations for 400》. 


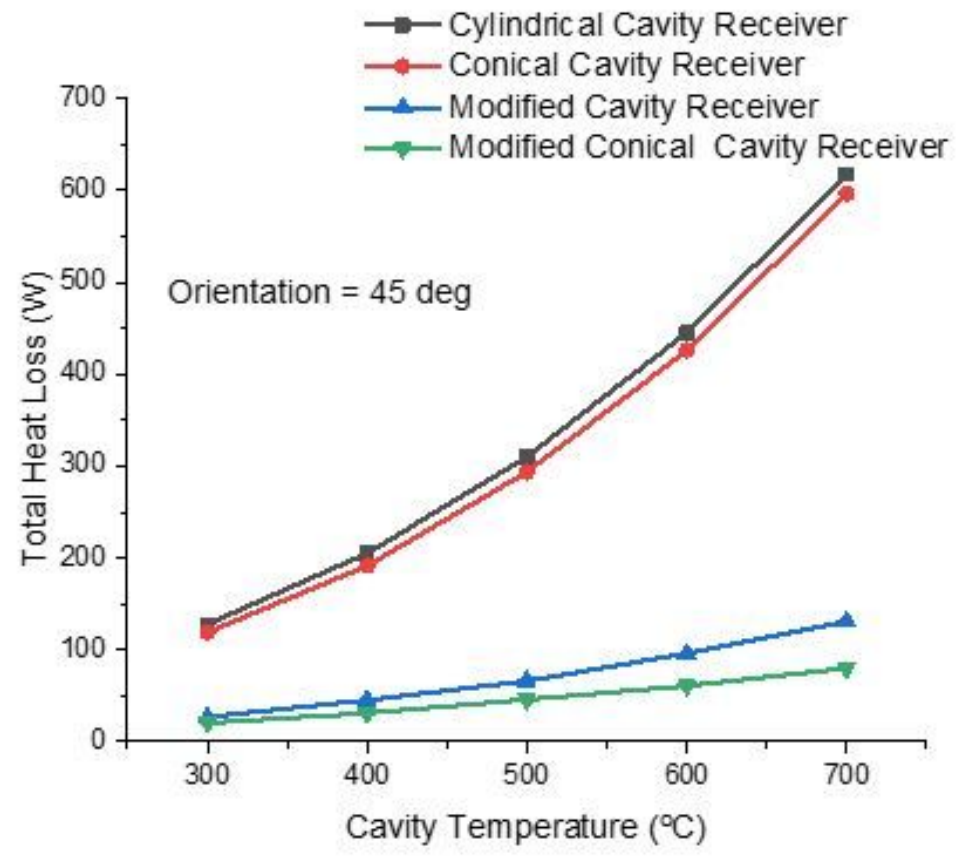

(a)

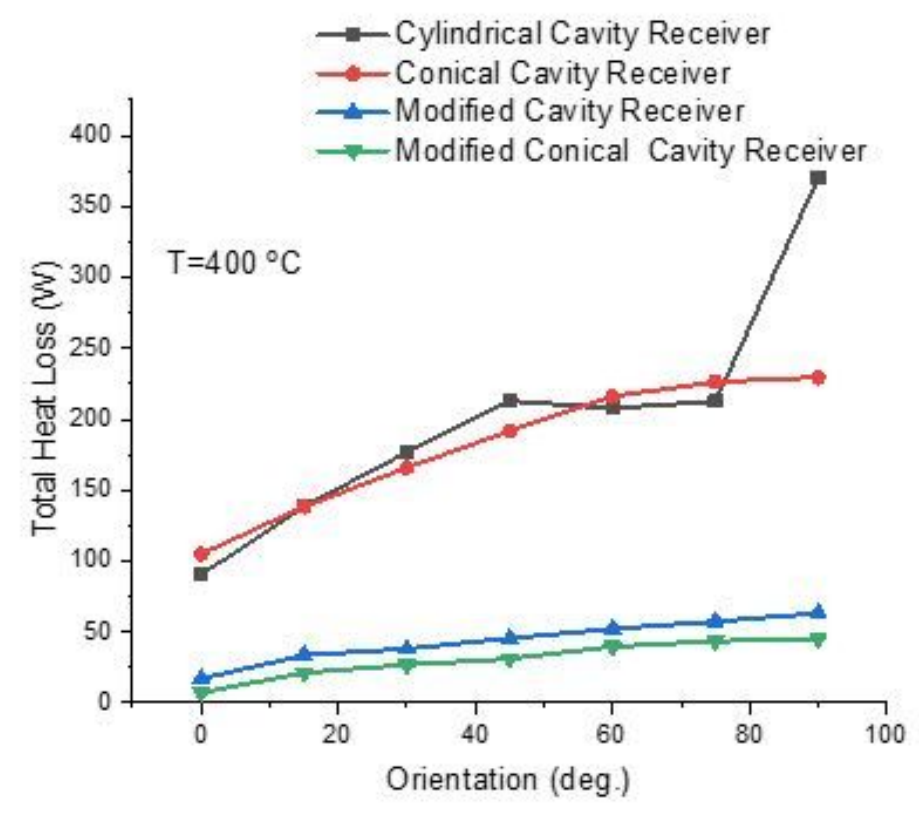

(b)

\section{Figure 6}

Variation of total heat loss from the various cavity receivers (a) with respect to cavity temperature for $45^{\circ}$ orientation and (b) with respect to receiver orientation for $400 \rrbracket$ cavity temperature. 


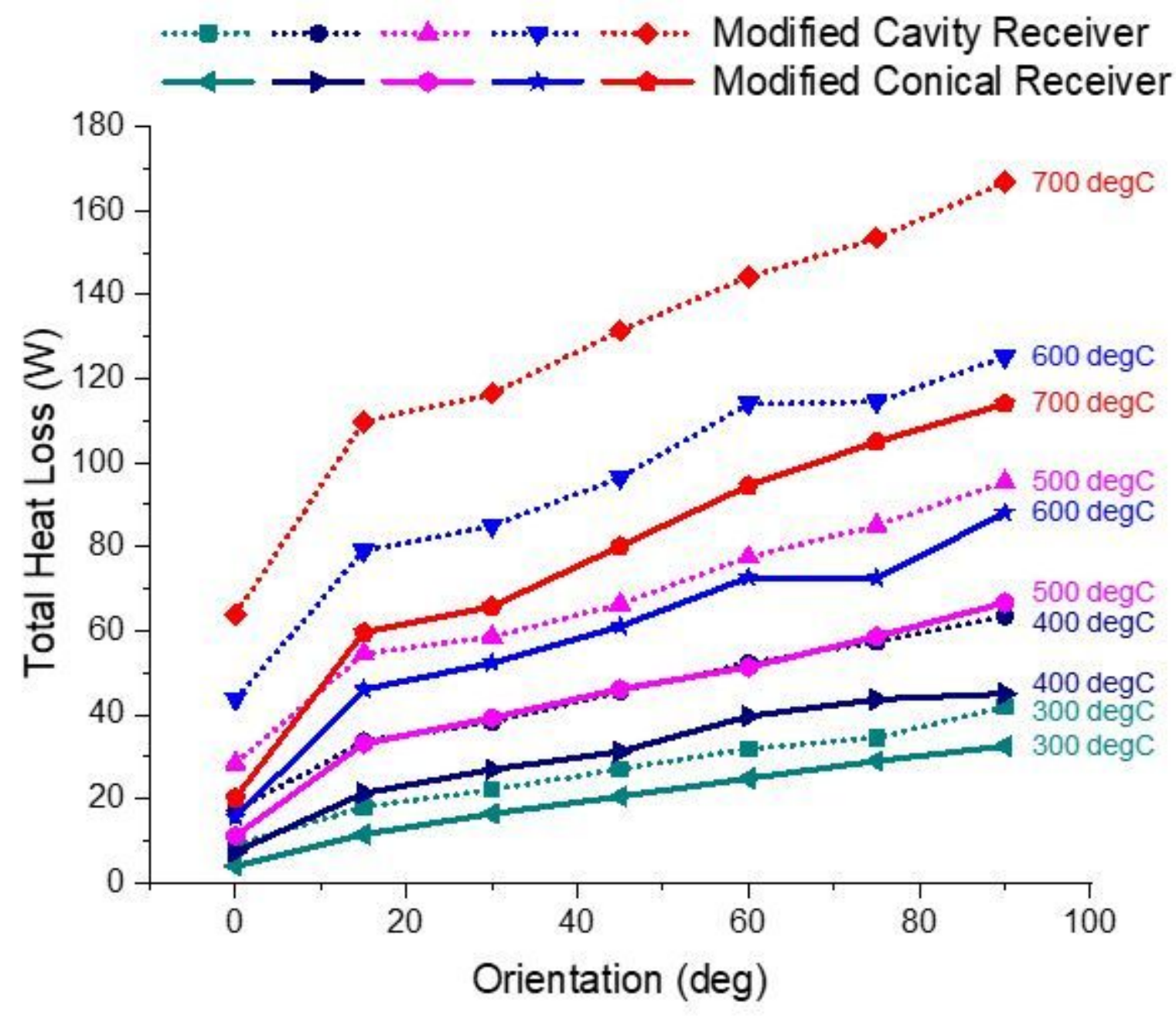

Figure 7

Illustrates the variation of total heat loss of the modified and modified conical cavity receivers for various orientations and temperatures. 